This item was submitted to Loughborough's Research Repository by the author.

Items in Figshare are protected by copyright, with all rights reserved, unless otherwise indicated.

\title{
Rapid manufacturing of bioceramic/polymer composite implants by selective laser sintering
}

PLEASE CITE THE PUBLISHED VERSION

PUBLISHER

(c) Inderscience Publishers

VERSION

AM (Accepted Manuscript)

LICENCE

CC BY-NC-ND 4.0

\section{REPOSITORY RECORD}

Hao, L., M.M. Savalani, Y. Zhang, K.E. Tanner, and Russell A. Harris. 2019. "Rapid Manufacturing of Bioceramic/polymer Composite Implants by Selective Laser Sintering". figshare.

https://hdl.handle.net/2134/5003. 
This item was submitted to Loughborough's Institutional Repository (https://dspace.lboro.ac.uk/) by the author and is made available under the following Creative Commons Licence conditions.

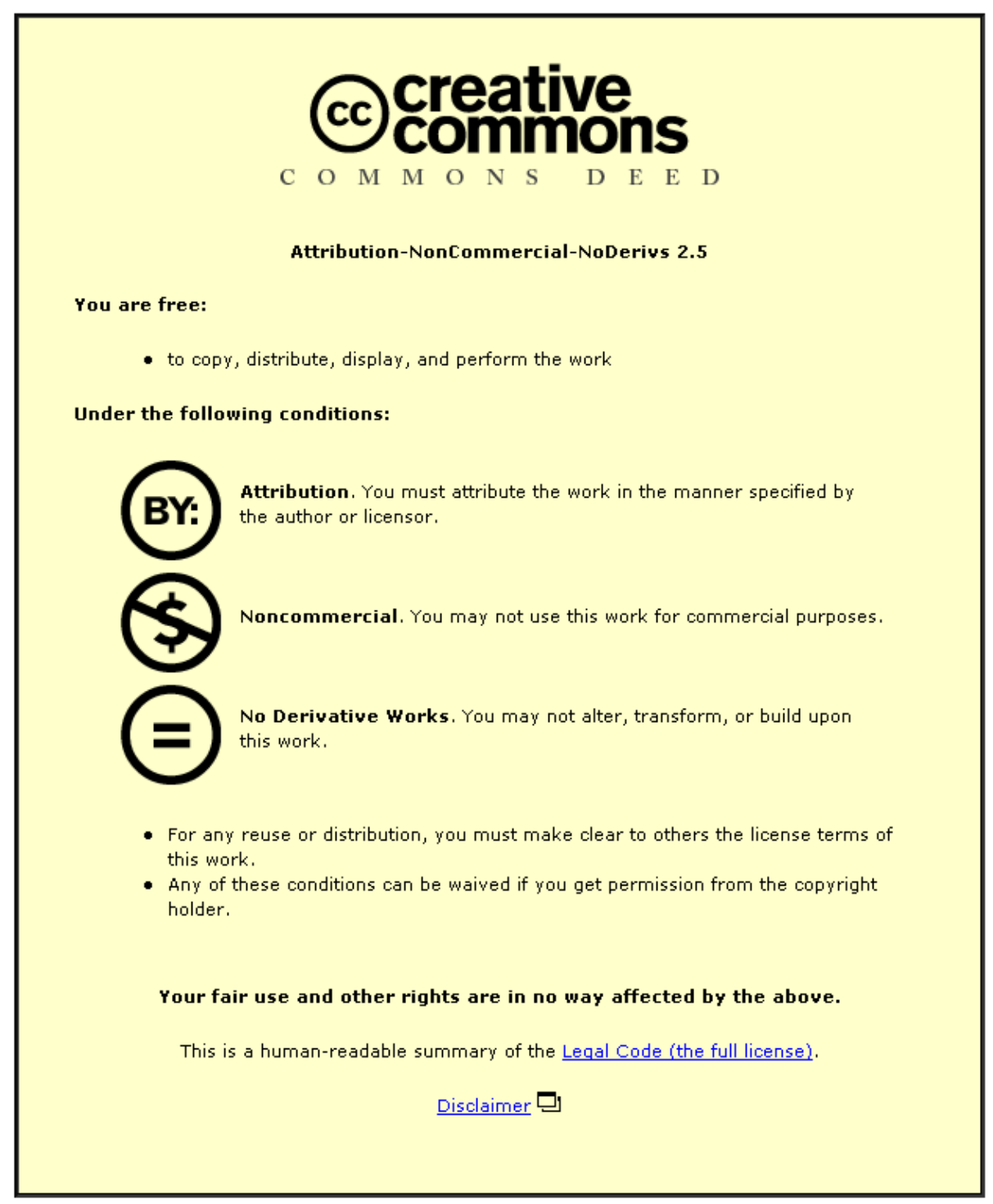

For the full text of this licence, please go to: http://creativecommons.org/licenses/by-nc-nd/2.5/ 


\title{
Rapid manufacturing of bioceramic/polymer composite
} implants by selective laser sintering

\author{
${ }^{1}$ L.Hao, ${ }^{1}$ M.M. Savalani, ${ }^{2}$ Y. Zhang, ${ }^{2}$ K.E. Tanner, ${ }^{1}$ R. A. Harris \\ ${ }^{1}$ Rapid Manufacturing Research Group, Wolfson School of Mechanical and Manufacturing
} Engineering, Loughborough University, Loughborough, Leicestershire, LE11 3TU, United Kingdom

${ }^{2}$ Department of Materials, Queen Mary University of London, Mile End Road, London, E1 4NS, United Kingdom

\begin{abstract}
Selective laser sintering (SLS), which is a additive rapid manufacturing technique, it is capable of producing the required product directly and automatically from a 3D computer model representation, have been selected to build implant and scaffold structures using composite materials consisting of a polymer and a bioactive ceramic. Hydroxyapatite (HA), a bioceramic that encourages bone apposition, can be combined with high density polyethylene (HDPE), a biocompatible polymer, to form a material with appropriate stiffness, toughness and bioactivity for use in the body. A miniature SLS system was built to minimize the usage of the expensive experimental material. It was used to determine the $\mathrm{CO}_{2}$ laser sintering operation window of the HA/HDPE composites and to investigate the effect of the process parameters on the surface morphology of the sintered HA/HDPE layer. The potential of SLS for the rapid manufacture of customised implants using HA/HDPE composite is demonstrated by the sintering of a 5-layer HA-HDPE block.
\end{abstract}

\section{Instruction}

Rapid manufacturing, also known as solid free form fabrication, is an advanced mouldless manufacturing technique which allows physical parts to be created immediately, directly and 
automatically from a three dimensional (3D) computer-aided-design [CAD] model. Unlike conventional machining processes which involve the removal of materials from a stock, rapid manufacturing builds parts by selectively adding materials, layer by layer with each layer representing the shape of the cross-section of 3D model. This additive approach permits complex shapes to be produced and enables the economically viable production of customised products. Selective laser sintering, a specific type of additive rapid manufacturing technique, employs high precision laser scanning system to sinter selectively powder to form layers. Subsequent layers are built directly on top of previously sintered layers with new layers of powder being deposited by a roller. SLS process deals with powdered materials such as polymers, ceramics, metals and mixed composites. SLS process allows a wide range of materials to be used and it is a building process without the need for supports, which enables its use in a vast range of applications. SLS was initially used to produce of physical models of human anatomy for surgical planning, training and design of customised implants in the medical field such as models of two skulls (Berry et al. 1997). The potential of SLS for directly fabricating the implants or tissue scaffold has been investigated using Nylon-6 (Das et al. 2003), polycaprolactone (PCL) (Williams et al. 2005), blended HA/polyetheretherketone (PEEK) (Tan et al. 2003) and HA/polyvinyl alcohol (PVA) composites (Chua et al. 2004).

The development of biomaterials has shifted from monoliths to composites in recent years, because metals are too stiff to prevent stress shielding, polymers tend to be too flexible and low strength to meet the mechanical demands for an internal fixation device, and bioceramics are too brittle for weight bearing. By controlling the volume fraction and distribution of the second phase in the composite, the properties of composites can be tailored to meet mechanical and physiological requirements as an implant (Bonfield 1988). HA has been successfully combined with different thermoplastics (polyethylene, polypropylene) to produce composites. For example, HA-reinforced high-density polyethylene (HDPE) composites (HAPEX ${ }^{\mathrm{TM}}$ ) have been de- 
veloped successfully for clinical application such as orbital floor implants for patients suffering from post-enucleation socket syndrome and in middle ear implants (Downes et al. 1991).

The production methods for available HA/polymer implants are currently restricted. The HA/polymer matrix material is compounded in powder form and subsequently moulded to form the bulk material. The matrix material can be processed into several formats, including extruded solids, pellets and powders, but consequently is slow to produce as implant devices. Presently, HA/polymer implants are shaped by conventional techniques such as moulding or cutting which have several disadvantages when used in implant production. For example, these indirect techniques require more process steps, they are less automated, they have high material waste (cutting techniques), or they require individual tooling for one-off jobs (moulding techniques). These conventional techniques also impose geometrical restrictions on the shapes that may be produced. In addition, the conventional techniques impose a long lead-time for implant production and present a stumbling block that dilutes many of the advantages beyond even those of unlimited shape complexity and increased speed and efficient of treatment.

The rapid manufacturing of the HA/polymer implant has advantages beyond even those of unlimited shape complexity and increased speed and efficiency of treatment. This technique is therefore has the potential to provide customised implants to improve bone defect repair for individual patients and enhance the longevity of the implants by providing a more secure fit (Mercuri et al. 1995). Further additional unique and exciting characteristics exist that may using SLS, these are controlled compositional and geometrical structure.

\section{The composite grains for SLS sintering}

According to the preparing method, the composite grains for SLS sintering can be divided into three groups, namely separate grains, coated grains and composite grains. Separate grains are prepared by the physical blending or mixture of structure particles and binder particles. How- 
ever, it is important ensure a homogenized particle mixture due to the differences in density and size of the particle. If the powder particles are not well mixed, segregation of different elements can take place during the deposition of the powder onto the powder bed or happen after melting. Coated grains are a structural material coated by a binder material. Composite powder grains contain both the binder and structural material within each individual grain, thus avoiding segregation of the different elements.

In this study, composites grains consisting of HA and HDPE were prepared for SLS process. The HDPE (Rigidex HM4560XP, BP Chemicals Ltd) and HA particles (P218R, Plasma Biotal Ltd., UK) were used to produce HA/HDPE composites. The HA particles have a median size $\left(d_{0.5}\right)$ of $3.80 \mu \mathrm{m}$ (Zhang and Tanner 2003). The processing route of HA/HDPE composite materials consists of blending, compounding and powderising. HA and HDPE powders with $40 \%$ HA by volume were mixed using a high speed commercial blender (Kenwood Mixer). The mixture of HA and HDPE was then fed into the extruder hopper of a twin screw extruder (Betol BTS40L) for compounding. Then, the extrudate was pelletized and pelletized HA-HDPE composites were powderized in an ultra centrifugal mill (Retsch Powderizer) using sieve of 0.250 mm. Liquid nitrogen was used as a coolant to cool and thus embrittle the composite during powderizing.

Differential scanning calorimetry (DSC) was used to analyse the melting point of HA/HDPE. The melting temperature of the HA/HDPE composites is $136.47^{\circ} \mathrm{C}$ as shown in Figure 1 . The scanning electron microscopy (SEM) was used to investigate the morphology of composites powders following sputter coating with gold. The HA/HDPE powders are in irregular particle shape and most of the particles have are from 100 to $150 \mu \mathrm{m}$ across as shown in Figure 2. 


\section{SLS systems Development}

A miniature SLS system was built to minimize the usage of the expensive experimental material. The system includes an "experimental powder bed chamber" and $\mathrm{CO}_{2}$ laser system but functions like any commercial SLS system.

\subsection{Experimental powder bed chamber}

The "experimental powder bed chamber" with a rig and transparent plastic box provides SLS processing platform. The rig, shown in Figure 3, has two $103 \mathrm{~mm}$ diameter cylinders serving as the operation and feed powder beds. A roller is used to spread and layer the powder. Three units control its drive motors for the build and feed pistons and its roller. A zinc selenide glass window is located on the upper cover of the chamber for transmission of the applied laser radiation.

An inert atmosphere is essential to ensure minimize oxidation. By filling nitrogen gas into the closed chamber, an inert atmosphere was created with oxygen level being maintained below 5.5 \%. An oxygen sensor (Pico Technology) is integrated to the chamber to measure the oxygen level.

Two heater bands and one infrared lamp were installed to preheat the powders to reduce its laser power required and the distortion in the sintering process. Heater bands with PID temperature controllers surrounded the centre area of its build cylinder to heat up the powder. A $1 \mathrm{Kw}$ rectangular infrared lamp was situated at the upper area of side plastic wall to heat up the surface of the powers by radiation. Since the lamp does not radiate perpendicular to the surface, the powders at different areas were not heated evenly due to the varied radiation distances. In order to minimise this problem, the sintering experiments conducted at the relatively small region to avoid the big difference in powder bed temperature. The current system allows us to investigate the potential of the SLS to build up the HA-HDPE part and effect of laser process parameters on the sintering. The "experimental powder bed chamber" developed allows the use of less of the 
expensive composite powders, controlled sintering atmosphere and its possibility to use different laser systems.

Subsequently, the experimental system has been improved by replacing the infrared lamp with a ring shape heater element which can both heat up the powders and allow the laser beam to go through. The thermal image analysis shows that surface temperature of the powders at different areas of building cylinder only varies slightly (Figure 4).

\subsection{Laser system}

A Synrad 48-1-28 carbon dioxide $\left(\mathrm{CO}_{2}\right)$ laser has a wavelength of $10.6 \mu \mathrm{m}$ and an output power of $0.1-10 \mathrm{~W}$ in continuous mode. The scanning speed of the laser beam varies from 0.2 to $10,000 \mathrm{~mm} \mathrm{~s}^{-1}$. For the sintering, the laser beam was focused to a spot size of $193 \mu \mathrm{m}$ at a focal length of $421 \mathrm{~mm}$.

Scan Spacing is defined as the distance between two adjacent scan vectors. The laser is coupled with a marking software called Winmark which does not provide this option. However, a resolution option is available which is measured in dots-per-inch (dpi). Hence, the higher the number of dots per inch is, the smaller the scan spacing vector, however, a means of quantification of this is needed. The system has limits between 0 to $1000 \mathrm{dpi}$, to provide a theoretical quantification of these values, geometrical calculations from the values used on the sinterstation (3D systems) have been used.

To equate the amount of overlap on each system:

$$
\frac{\operatorname{Exp}_{\text {SPOTSIZE }}}{\operatorname{Exp}_{\text {SCANSPACING }}}=\frac{3 D_{\text {SPOTSIZE }}}{3 D_{\text {SCANSPACING }}}
$$

Where spot size (3D sinterstation) $=454 \mu \mathrm{m}$; scan spacing (3D sinterstation) $=150 \mu \mathrm{m}$; spot size $($ experimental system $)=193 \mu \mathrm{m}$. Hence, scan spacing for the experimental system is 63.33 $\mu \mathrm{m}$. 


\section{SLS Laser Sintering of HA/HDPE}

Laser power and scanning speed determine the energy imparted to the layer in the SLS process. The energy imparted is termed the energy density and is assigned a dimension known as the Andrew number $\left(A_{N}\right)$ that measures the effective energy exposure of the lay built by SLS (Williams and Deckard 1998). The relationship is given by

$$
A_{N}=\frac{P}{V H S}
$$

Where $\mathrm{P}$ = laser power; $\mathrm{V}$ = scanning speed; HS = scan spacing.

The laser power imparts energy to the part by directly bombarding radiation on to the part of its bed during the scanning of a part section profile. As the amount of energy absorbed is determined by the duration of radiation on a unit area, the faster the laser beam travels, the less energy is absorbed. Thus, the amount of energy imparted, which will determine the sintering process, can be controlled by laser power and scanning speed.

Since the energy is a function of both laser power and scanning speed (that is, if either one is independently altered then such a change can be compensated for through an independent alternation of the other), it is necessary to experimentally determine the exact operating window for the laser sintering of HA/HDPE. Under the fixed scanning space applied, the scanning speed was varied from $300 \mathrm{~mm} \mathrm{~s}^{-1}$ to $4800 \mathrm{~mm} \mathrm{~s}^{-1}$ and the laser power was varied from $1.2 \mathrm{~W}$ to $9.6 \mathrm{~W}$ for the sintering experiments. The HA/HDPE layers were sintered successfully at the parameters shown in Figure 5. When the power was too low or scanning speed was too high, the layers were in general not sintered or very fragile. On the other hand, the layers typically became dark brown when the power was too high or scanning speed was too low. The colour change of the layer should be caused by the char in the SLS process. Figure 7 shows a 5-layer HA/HDPE block ( $4 \times$ $23 \mathrm{~mm}$ ) fabricated at $7.2 \mathrm{~W}$ and $1200 \mathrm{~mm} \mathrm{~s}^{-1}$. As the laser scanned at the speed of $1200 \mathrm{~mm} \mathrm{~s}^{-1}$, 
it only spend a few minutes in sintering this block which also including the powder deposition. This indicates the potential of the SLS process to rapid manufacture the customised shape product.

The different process parameters resulted in the different effects on the sintered layers. The layer fabricated at $3.6 \mathrm{~W}$ and $1200 \mathrm{~mm} \mathrm{~s}^{-1}$ presents apparently porous morphology with individual particle still being identified as shown in Figure 7 (a). In contract, the layer fabricated at 7.2 $\mathrm{W}$ and $1200 \mathrm{~mm} \mathrm{~s}^{-1}$ exhibits relative dense morphology owing to the fusion of the particles as shown in Figure 7(b).

Figure 8 shows the morphology of a HA/HDPE matrix particle in the layer fabricated at $4.8 \mathrm{~W}$ and $1200 \mathrm{~mm} \mathrm{~s}^{-1}$. Small round particles with 3 to $10 \mu \mathrm{m}$ size, which is agreement with the measured size distribution, are HA particles in the matrix. The connections, which are appeared as the bridges between the gaps existing in the matrix, are formed by the melted HDPE in the laser sintering. Thus, the liquid-phase sintering would have been occurred in SLS processing. The main advantage of liquid-phase sintering is it provides the very fast initial binding, which is based on capillary forces, which can be very high. This transformation is faster than physical diffusion in solid state sintering. In addition, the matrix particle exhibits no segregation between the HA particle and HDPE, indicating the composite grains are suitable for laser sintering.

Figure 9 presents the morphology of HA particle exposed on the HA/HDPE layer fabricated at $9.6 \mathrm{~W}$ and $1200 \mathrm{~mm} \mathrm{~s}^{-1}$. Numerous HA particles were exposed on the HA/HDPE matrix particles, revealing that the HDPE polymer may be degraded or even burnt out under the higher laser power in the laser sintering process. This HDPE damage is because that the high power intensity focusing on small laser beam spot and overlapping of the beam on the surface could result in local effects on the substrate material. When the laser power is too high, it could result in the degradation or vaporisation of the polymer (HDPE). A number of its HA particles are as large as 20 to $40 \mu \mathrm{m}$, which is much larger than the $\mathrm{d}_{0.9}$ size of raw HA particles that which have 
been compounded in the HA/HDPE matrix. This shows that the volume of HA particles expanded in the laser sintering process. It may be that the air trapped inside the HA particle or HA/HDPE matrix particles has been released during the evaporation and undergoes a high temperature exothermic reaction and consequently, resulted in the volume expansion or even explosion. As shown in Figure 9, some HA particles were broken due to the explosion in the laser sintering process. The exposure of HA particles may benefit the bioactivity of the laser sintered HA/HDPE layer due to the well recognised bioactivity and osteoconductivity of the HA particles. However, the degraded HDPE or the residue of burned HDPE might cause negative effects on the mechanical property or the biological response and will be considered the future studies. The previous study (Rimell and Marquis 2000) showed that ultra high molecular weight polyethylene (UHMWPE) undergone degradation following the SLS process, however, the nature of the degradation of the UHMWPE is comparable to that produced by irradiation sterilization and may not degrade the properties to an unacceptable level for certain applications.

\section{Summary and Conclusions}

An "experimental powder bed chamber" has been developed to allow the use of less of the expensive material, provide a controlled sintering atmosphere and it possibility to use different laser systems.

An operating window exists for the $\mathrm{CO}_{2}$ laser sintering of $\mathrm{HA} / \mathrm{HDPE}$ composites. The processing parameters outside the operation window resulted in the either fragile layers or charred layers. The process parameters play an important role in the properties of the sintered layers. At relatively low laser power, the layers present a more porous surface morphology, whereas the layers fabricated at higher laser power exhibit a relatively dense morphology.

Composite grains are suitable for laser sintering since no segregation between the HA particle and HDPE is exhibited in the matrix particle. At high laser power, the HDPE may be degraded 
or burned and HA particles were exposed on the matrix particles and may be expanded or exploded to the larger volume than the raw HA particle. The exposed HA particle may benefit to the bioactivity, while the degraded or burned HDPE may cause the negative effect on the properties of the sintered parts.

The successful building of HA/HDPE block attested that the SLS has the potential to fabricate HA/HDPE products and will provide the advantages of fast lead time and customised geometry over the conventional methods.

Future work will be conducted to investigate the controlling the porosity and pore interconnectivity by means of process parameters and using HA/HDPE powders with different particle sizes and investigating the mechanical properties and biocompatibility of SLS fabricated parts.

\section{Acknowledgement}

The authors would like to express their gratitude to the financial support from the UK Department of Health’s New \& Emerging Applications of Technology (NEAT E059). 


\section{References}

Berry, E., Brown, J. M., Connell, M., Craven, C. M., Efford, N. D., Radjenovic, A. \& Smith, M. A. 1997. Preliminary experience with medical applications of rapid prototyping by selective laser sintering. Medical Engineering \& Physics, 19(1): 90-96.

Bonfield, W. 1988. Hydroxyapatite-reinforced polyethylene as an analogous material for bone replacement. Annuals of New York Academic Science, 523: 173-177.

Chua, C. K., Leong, K. F., Tan, K. H., Wiria, F. E. \& Cheah, C. M. 2004. Development of tissue scaffolds using selective laser sintering of polyvinyl alcohol/hydroxyapatite biocomposite for craniofacial and joint defects. Journal of Materials Science: Materials in Medicine, 15(10): 1113-1121.

Das, S., Hollister, S. J., Flanagan, C., Adewunmi, A., Bark, K., Chen, C., Ramaswamy, K., Rose, D. \& Widjaja, E. 2003. Computational design, freeform fabrication and testing of Nylon-6 tissue engineering scaffolds. Rapid Prototyping Technologies, Dec 3-5 2002, Boston, MA, United States

Downes, R. N., Vardy, S., Tanner, K. E. \& Bonfield, W. 1991. Hydroxyaptite-Polyethylene Composite in Ophthalmic Surgery, Bioceramics 4:239-246, W. Bonfield, ed.

Mercuri, L. G., Wolford, L. M., Sanders, B., White, D., Hurder, A. \& Herderson, W. 1995. Custom CAD/CAM total temporomandibular joint reconstruction system: preliminary multicenter report. Journal of Oral Maxillofacial Surgery, 53: 106-115.

Rimell, J. T. \& Marquis, P. M. 2000. Selective laser sintering of ultra high molecular weight polyethylene for clinical applications. Journal of Biomedical Materials Research, 53(4): 414-420.

Tan, K. H., Chua, C. K., Leong, K. F., Cheah, C. M., Cheang, P., Abu Bakar, M. S. \& Cha, S. W. 2003. Scaffold development using selective laser sintering of polyetheretherketonehydroxyapatite biocomposite blends. Biomaterials, 24(18): 3115-3123.

Williams, J. D. \& Deckard, C. R. 1998. Advances in modeling the effects of selected parameters on the SLS process. Rapid Prototyping Journal, 4(2): 90-100.

Williams, J. M., Adewunmi, A., Schek, R. M., Flanagan, C. L., Krebsbach, P. H., Feinberg, S. E., Hollister, S. J. \& Das, S. 2005. Bone tissue engineering using polycaprolactone scaffolds fabricated via selective laser sintering. Biomaterials, 26(23): 4817-4827. 
Zhang, Y. \& Tanner, K. E. 2003. Impact behaviour of hydroxyapatite reinforced polyethylene composites. Journal of Materials Science: Materials in Medicine, 14(1): 63-68. 
Figure 1. DSC analysis of HA/HDPE powder with 40 volume \% HA powder

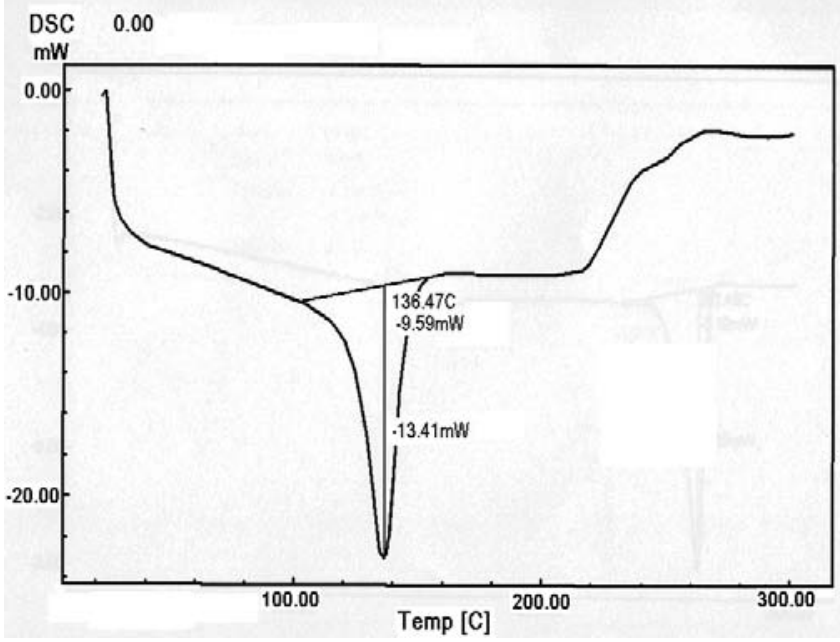

Figure 2. SEM micrograph of HA/HDPE composite powder with 40 volume \% HA ratio $($ marked bar $=100 \mu \mathrm{m})$

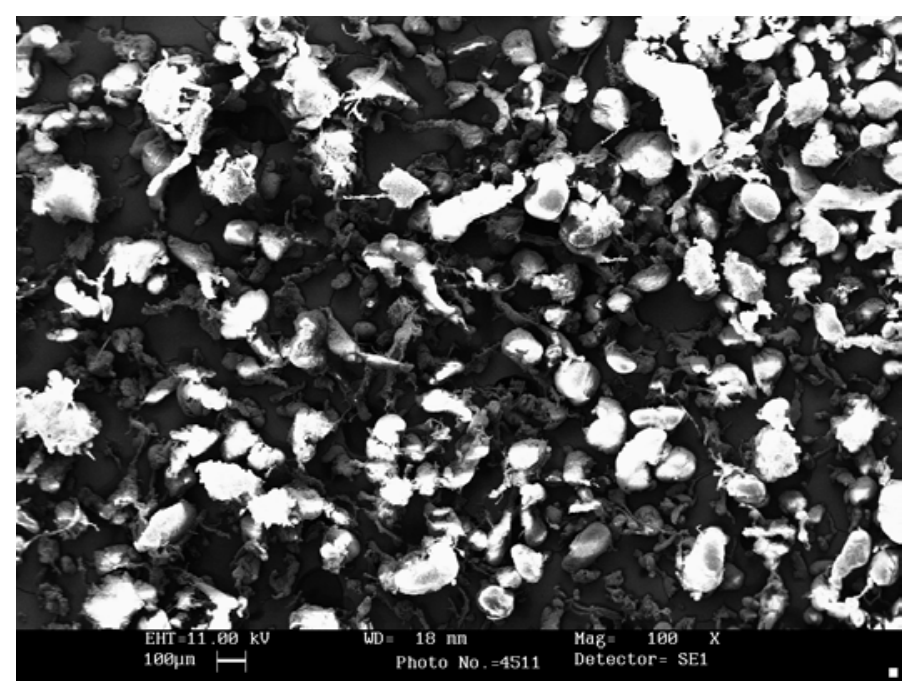


Figure 3. Photograph of experimental chamber showing the build powder bed with the feed powder bed behind and the feed roller.

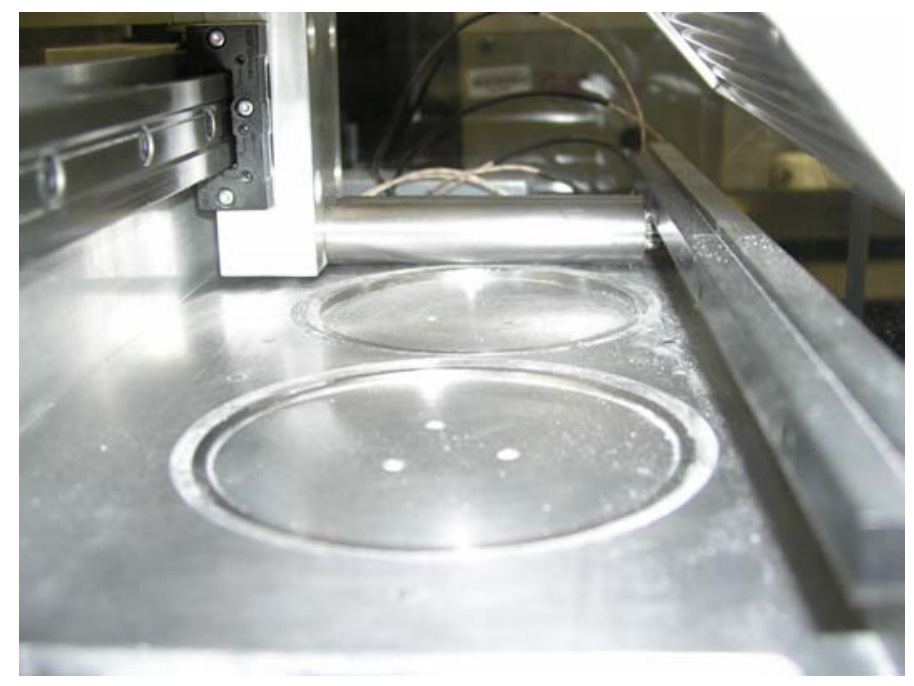

Figure 4. Temperature distribution of the powders in building cylinder under the circlular heat element
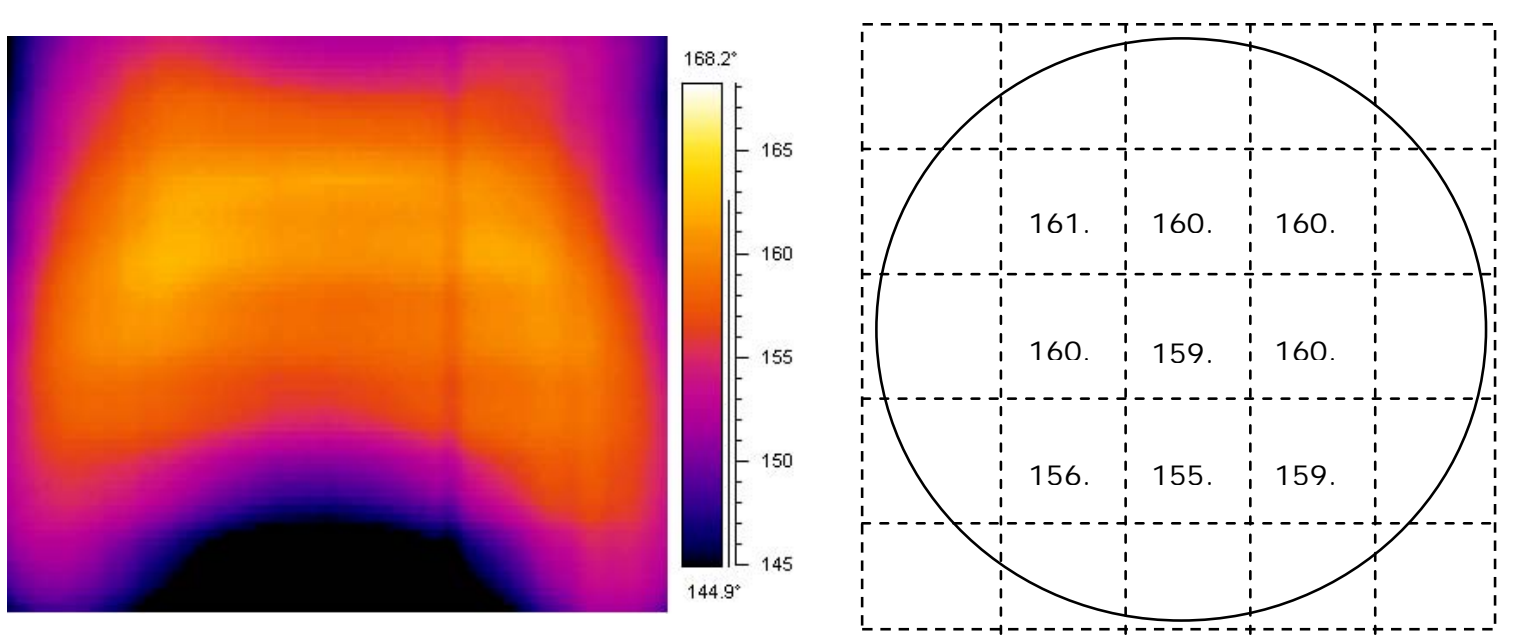
Figure 5. Schematic showing the operating window for the laser sintering of HA/HDPE composite for different laser power and scanning speeds)

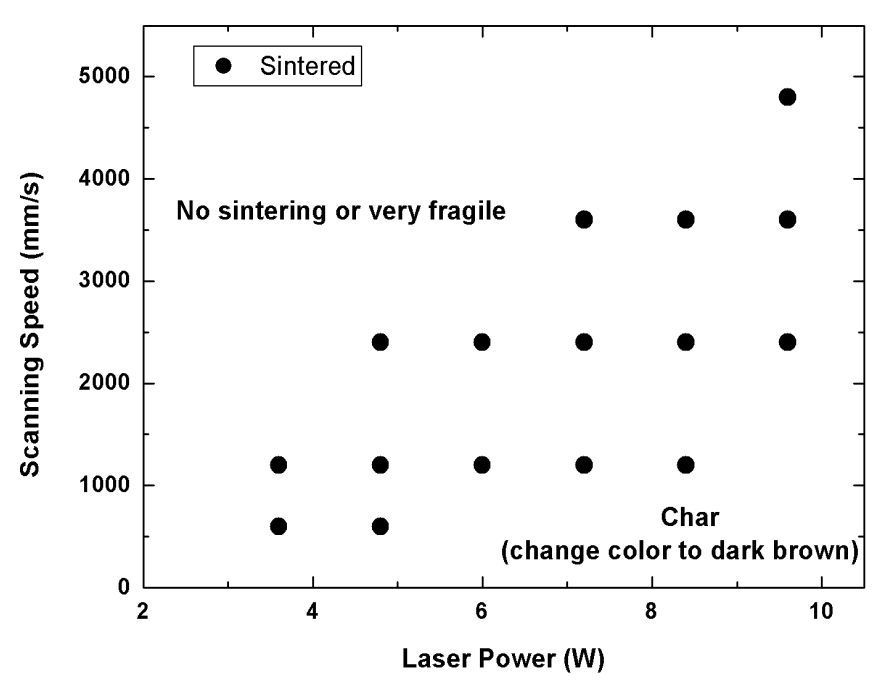

Figure 6. A 5-layer HA/HDPE block (40 vol \% HA) with $0.4 \mathrm{~mm}$ layer thickness fabricated by this SLS experimental system (Laser power of 7.2 W and scanning speed of $1200 \mathrm{~mm} \mathrm{~s}^{-1}$ ). 
Figure 7. SEM micrograph of surface morphology of sintered layers with 40 vol \% HA composite and laser power of (a) 3.6W and (b) $7.2 \mathrm{~W}$ at scanning speed of $1200 \mathrm{~mm} \mathrm{~s}^{-1}$ (marked bar $=$ $100 \mu \mathrm{m})$.

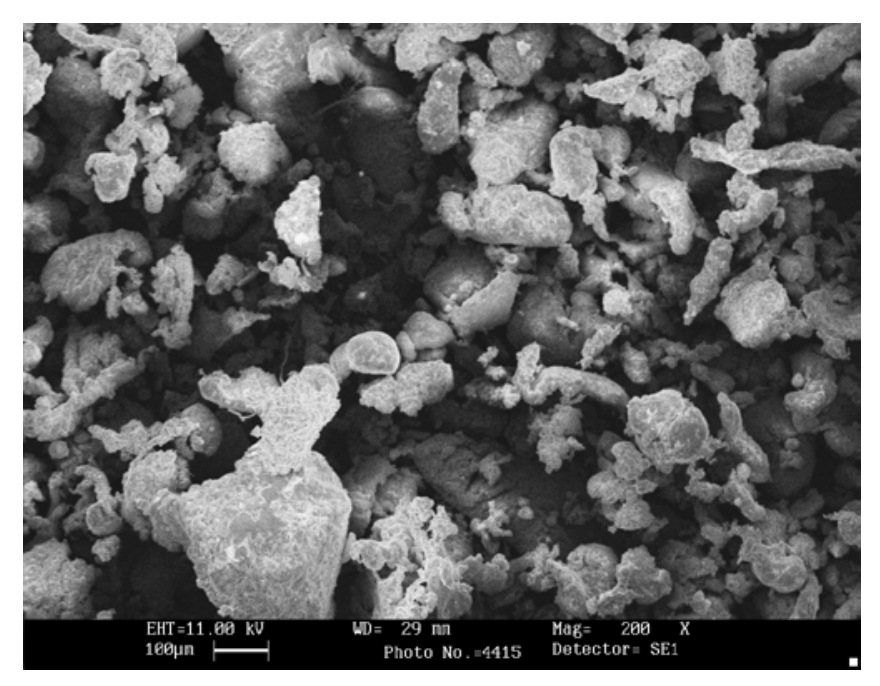

(a)

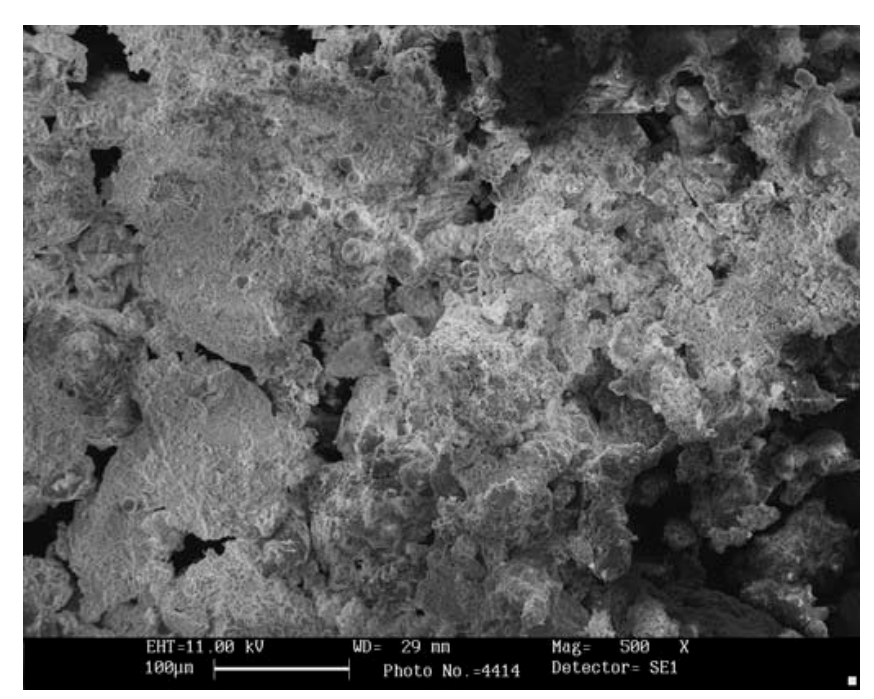

(b) 
Figure 8. The SEM image of HA/HDPE particles sintered at $4.8 \mathrm{~W}$ and $1200 \mathrm{~mm} \mathrm{~s}^{-1}$

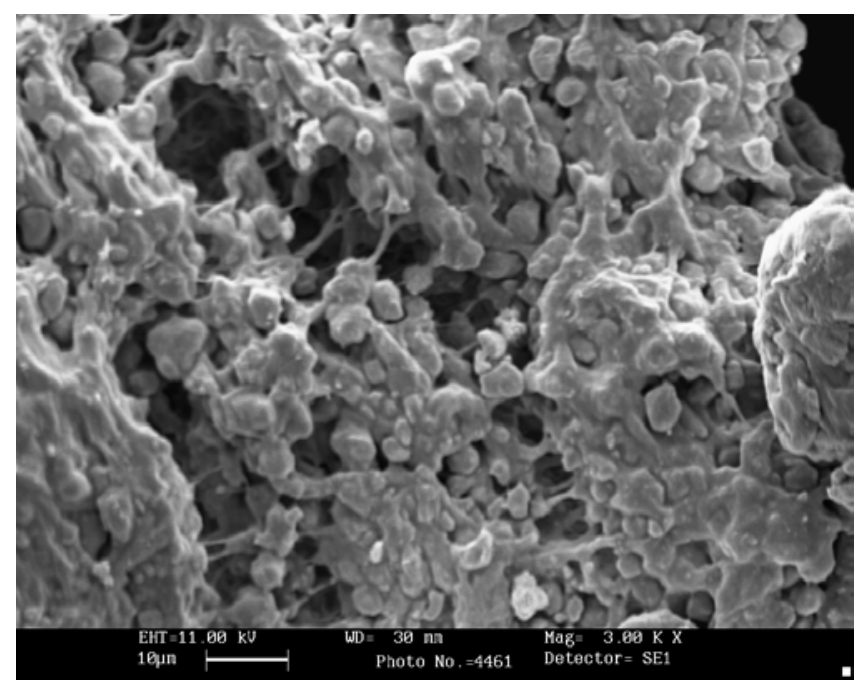

Figure 9. The SEM image of HA particles on HA/HDPE layer sintered at $9.6 \mathrm{~W}$ and $1200 \mathrm{~mm}$ s1 showing exposure of HA particle and damage its HDPE matrix (marked bar $=30 \mu \mathrm{m}$ ).

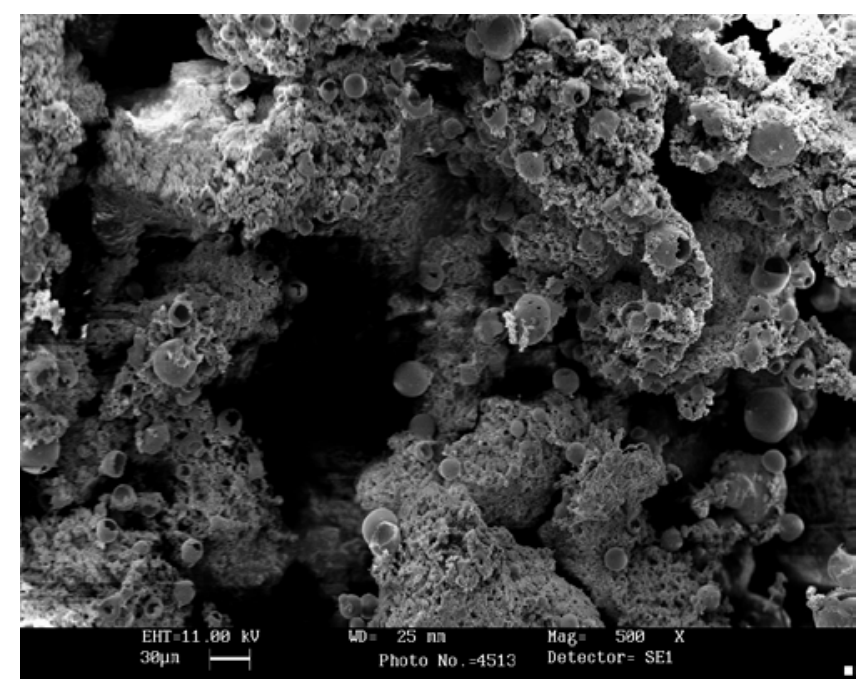

